\title{
Penerapan Modul Pembelajaran Sains dengan Media Pembelajaran Gamelan untuk Meningkatkan Pemahaman dan Aplikasi Konsep Siswa SMP Negeri 3 Sleman
}

\author{
Eko Nursulistiyo \\ Pendidikan Fisika FKIP Universitas Ahmad Dahlan Yogyakarta \\ Surat-e: ekonur.uad@gmail.com
}

Telah dilakukan penelitian untuk mengetahui peningkatan pemahaman dan aplikasi konsep getaran, gelombang dan bunyi siswa yang menggunakan modul dengan media pembelajaran gamelan dibandingkan dengan siswa yang belajar secara konvensional di SMP N 3 Sleman kelas VIII. Gamelan digunakan sebagai media pembelajaran dalam beberapa konsep getaran gelombang dan bunyi agar siswa dapat belajar secara kontekstual dan diharapkan apresiasi terhadap alat musik tradisional gamelan dapat meningkat. Pemahaman dan aplikasi konsep siswa diukur dengan menggunakan pretest dan postest.

Hasil observasi menunjukkan bahwa proses pembelajaran dapat berjalan sesuai dengan RPP yang direncanakan. Hasil pengujian menunjukkan rata-rata nilai pre-test 39,79 dan rata-rata post-test 83,I5 pada kelas eksperimen. Uji paired sample test menunjukkan bahwa nilai probabilitas yang diperoleh adalah 0,000. Untuk kelas kontrol rata-rata nilai pre-test 44,47 dan rata-rata post-test 78,53. Hasil uji paired sample t-test untuk kelas kontrol menunjukkan nilai probabilitas yang diperoleh adalah 0,000. Kedua kelas menunjukkan nilai probabilitas $\mathrm{p}<0,05$. Hal ini menunjukkan bahwa ada perbedaan signifikan antara pre-test dan post-test pada kelas eksperimen dan kelas kontrol. Dengan kata lain pemahaman konsep dan aplikasi konsep siswa di kelas eksperimen dan kelas kontrol meningkat. Nilai rata-rata gain skor untuk kelas eksperimen adalah 43,I5 dan untuk kelas kontrol adalah 34,06. Berdasarkan perhitungan uji independent sample t-test diperoleh nilai probabilitas $0,003<0,05$. Hal ini menunjukkan bahwa terdapat perbedaan gain-score yang signifikan antara kelas eksperimen dan kelas kontrol. Kelas eksperimen yang menggunakan modul pembelajaran sains dengan media pembelajaran gamelan menunjukkan peningkatan pemahaman dan aplikasi konsep lebih tinggi daripada kelas kontrol yang melakukan pembelajaran secara konvensional.

Kata kunci: pemahaman dan aplikasi konsep, modul, media pembelajaran gamelan

\section{Pendahuluan}

Gamelan adalah salau satu warisan budaya Indonesia yang harus terus dilestarikan. Wayang diakui UNESCO pada 7 November 2003 sebagai masterpiece of oral and intangible haritage of humanity (http://sosbud.kompasiana.com/2010/06/19/budayaindonesia-yang-di-akui-unesco). Gamelan sebagai pengiring pergelaran wayang seharusnya juga dilestarikan. Di satu sisi, apresiasi generasi muda terhadap seni gamelan semakin rendah; di sisi lain, perkembangan musik-musik di barat sekarang ini banyak yang berpaling ke wilayah timur, termasuk seni gamelan yang dimiliki oleh bangsa Indonesia (Y.T.C Pramudi et al, 2010). Gamelan tidak begitu populer di kalangan mereka.

Konsep kebudayaan dapat didefinisikan sebagai keseluruhan cara bertingkah laku manusia dalam kehidupannya yang menjadi suatu identitas (Y.T.C Pramudi et al, 2010). Budaya Indonesia adalah hasil dari gabungan budaya-budaya unggulan daerah. 
Gamelan sebagai budaya daerah adalah akar dari budaya nasional. Apabila apresiasi terhadap gamelan hilang maka budaya bangsa akan ikut tergerogoti dan akhirnya akan hilang juga. Ancaman nyata yang kita hadapi adalah jika ekspresi budaya tradisional yang kita miliki hilang atau diklaim oleh pihak lain maka identitas sebuah bangsa Indonesia akan ikut menghilang (Dadan S, 2008).

Gamelan jarang sekali digunakan dalam proses pembelajaran fisika. Hal ini dikarenakan belum adanya media pembejaran atau bahan ajar yang didalamnya terkandung materi atau konsep fisika yang digali dari gamelan untuk diajarkan kepada siswa. Pengembangan modul pembelajaran sains dengan media pembelajaran gamelan ini telah dilakukan oleh Eko (2012) dan menghasilkan modul pembelajaran sains yang menggunakan media pembelajaran gamelan yang layak untuk digunakan dalam proses pembelajaran di tingkat SMP.

Penelitian ini bertujuan untuk mengetahui dan membandingkan peningkatan pemahaman dan aplikasi konsep getaran gelombang dan bunyi antara siswa yang melakukan pembelajaran konvensional dan siswa yang melakukan pembelajaran dengan menggunakan modul pembelajaran sains dengan media pembejalaran gamelan.

\section{Landasan Teori}

\section{Teori pembelajaran konstruktivisme dan modul}

Menurut filsafat kontruktivisme pengetahuan itu adalah bentukan (kontruksi) kita sendiri yang sedang menekuninya (Paul Suparno, 2007:8). Siswa tidak akan mendapatkan pengetahuan apapun apabila dia tidak mengkonstruksi atau membangun pengetahuanya sendiri. Menurut Bruce Joyce (2009:I4), sikap kontrukstivisme adalah bahwa pengetahuan tidak sekedar ditransmisikan oleh guru atau orang tua akan tetapi mau tidak mau harus dibangun dan dimunculkan sendiri oleh siswa agar mereka dapat merespon informasi dalam lingkungan pendidikan.

Modul adalah alat pembelajaran mandiri yang selaras dengan teori pembelajaran konstruktivisme tersebut. Menurut Sofan Amri dan Iif Khoiru Ahmadi (2010:197), pembelajaran dengan modul adalah pembelajaran mengenai suatu bahasan tertentu yang disusun secara sistematis, operasional dan terarah untuk digunakan oleh peserta didik, disertai dengan pedoman penggunaanya oleh guru.

\section{Pemahaman dan aplikasi konsep}

Menurut Louise Poulson \& Mike Wallace (2004:24), terdapat lima proyek intelektual yaitu pengetahuan-untukpemahaman, pengetahuan untuk evaluasi kritis, pengetahuan untuk tindakan, instrumentalisme, dan refleksi tindakan. Menurut
Airasian et al (200I: 70), Siswa dikatakan memahami jika mereka dapat mengkonstruksi makna dari pesan instruksional termasuk secara oral, tertulis, dan grafik. Berdasarkan definisi ini Airasian et al (200I :70) mengklasifikasi proses kognitif yang termasuk dalam kategori pemahaman yaitu ; (I). Menginterpretasikan (Interpreting), (2). Penyebutan contoh-contoh (Exemplying), (3). Mengklasifikasikan (Classifying), (4). Meringkas (Summarizing), (5). Menyimpulkan (Inferring), (6). Membandingkan (Comparing), (7). Menjelaskan (Explaining). Pemahaman konsep sains pada materi getaran gelombang dan bunyi adalah mengkonstruksi makna dari pesan instruksional termasuk secara lisan, tertulis, dan grafik dari konsep sains pada materi getaran, gelombang dan bunyi untuk dikomunikasikan atau digunakan.

Menurut Airasian et al (200I: 77), aplikasi melibatkan penggunaan prosedur untuk menyelesaikan permasalahan atau menampilkan latihan. Kategori aplikasi memuat dua macam proses kognitif yaitu eksekusi dan implementasi. Eksekusi dilakukan jika tugas yang diberikan adalah latihan. Implementasi dilakukan jika tugas yang diberikan adalah sebuah masalah. Aplikasi konsep sains pada materi getaran gelombang dan bunyi adalah kemampuan untuk menggunakan konsep untuk memecahkan soal yang berupa latihan atau masalah pada materi getaran gelombang dan bunyi.

Berdasarkan uraian mengenai pemahaman dan aplikasi konsep diatas, definisi pemahaman dan aplikasi konsep pada materi getaran gelombang dan bunyi dalam penelitian ini adalah mengkonstruksi makna dari pesan instruksional termasuk secara lisan, tertulis, dan grafik dari konsep sains pada materi getaran, gelombang dan bunyi untuk dikomunikasikan dan menggunakan konsep tersebut untuk memecahkan soal yang berupa latihan atau masalah pada materi getaran, gelombang, dan bunyi.

\section{Metode Penelitian/Eksperimen}

\section{Desain penelitian}

Penelitian ini menggunakan desain penelitian pre-test posttest control group design yang diperlihatkan pada tabel I. Proses pembelajaran konvensional dilakukan dengan menerapkan proses pembelajaran seperti biasa dengan metode ceramah dibantu dengan bahan ajar buku cetak. Proses pembelajaran dengan modul pembelajaran sanis menggunakan media pembelajaran gamelan dilakukan dengan menggunakan modul pembelajaran sains dengan media pembelajaran gamelan yang telah dikembangkan oleh Eko (2012). Pelaksanaan proses pembelajaran dilakukan dalam 5 kali pertemuan.

Tabel I. Pre-test post-test control group design

Kelompok Pre-test Treatment Post-test

\begin{tabular}{llll}
\hline $\mathrm{A}$ & $\mathrm{TI}$ & $\mathrm{XI}$ & $\mathrm{T} 2$ \\
$\mathrm{~B}$ & $\mathrm{TI}$ & $\mathrm{X} 2$ & $\mathrm{~T} 2$ \\
\hline
\end{tabular}

$\mathrm{A}=$ Kelompok eksperimen
$\mathrm{B}=$ Kelompok kontrol
$\mathrm{TI}=$ Pre-test untuk mengetahui kemampuan awal 
$\mathrm{T} 2=$ Post-test untuk mengetahui kemampuan akhir

$\mathrm{XI}=$ Proses pembelajaran dengan menggunakan modul

$\mathrm{X} 2=$ Proses pembelajaran dengan buku cetak (konvensional)

Subjek penelitian adalah siswa SMP N 3 Sleman kelas VIII semester 2 tahun ajaran 20II/2012. Kelas VIII F dengan jumlah siswa 33 digunakan sebagai kelas eksperimen dan kelas VIII D dengan jumlah siswa 32 sebagai kelas kontrol.

\section{Analisis data}

Uji validitas, reabilitas, daya beda dan tingkat kesukaran dilakukan pada soal pretest dan postest. Uji validitas dan reabilitas dilakukan dengan menggunakan software SPSS. Uji daya beda dan tingkat kesukaran dilakukan dengan menggunakan sofware ITEMAN.

Uji homogenitas dilakukan di awal penelitian pada kedua kelas untuk memperlihatkan bahwa dua kelas tersebut memiliki kesamaan skor awal. Uji Normalitas dilakukan pada hasil prestet untuk melihat apakah kelas tersebut berdistribuai normal atau tidak. Kedua tes ini akan menentukan apakah data akan diuji secara parametrik atau non parametrik. Jika data homogen dan normal maka uji yang dilakukan selanjutnya adalah uji parametrik dan apabila salah satu atau keduanya tidak terpenuhi maka uji yang diambil adalah uji nonparametrik.

Pretest dan postest pada kedua kelas dibandingkan. Gain skor yang menunjukkan kenaikan nilai prestest jugadibandingkan. Uji parametrik yang digunakan adalah uji paired samples t-test untuk data yang berpasangan dan independent samples t-test untuk data yang berdiri sendiri.

\section{Iv. Hasil dan Pembahasan}

Berdasarkan hasil dari pengamatan keterlaksanaan RPP pada kedua kelas diperoleh bahwa pada kedua kelas RPP dapat terlaksana I00\% (gambar I). Hal ini memperlihatkan bahwa seluruh perencaan proses pembelajaran dapat berjalan dengan baik di dalam kelas.

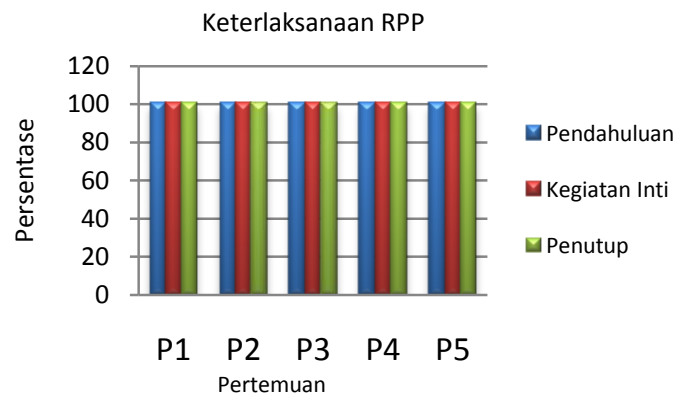

Gambar I. Histogram keterlaksanaan RPP.

Uji validitas soal dilakukan dengan menggunakan SPSS dengan syarat soal dapat dikatakan valid jika nilai probabilitas $[$ sig. (2-tailed) $] \leq$ dari taraf signifikan $(\alpha)$ sebesar 0,05. Dari 30
Penerapan Modul Pembelajaran Sains dengan Media Pembelajaran Gamelan untuk Meningkatkan Pemahaman dan Aplikasi Konsep Siswa SMP Negeri 3 Sleman

soal yang dibuat ternyata hanya I9 soal yang valid. Jumlah soal ini tidak ditambah karena semua indikator telah teruji dengan soal tersebut.

Tabel 2. Hasil Uji Reabilitas

Reliability Statistics

Cronbach's Alpha N of Items

,896

I9

Nilai koefisien reliabilitas soal dikatakan baik jika nilai koefisien yang diperoleh $\geq 0$ 0,60 (Imam Ghozali, 2002:I33). Berdasarkan hasil perhitungan diperoleh nilai koefisien reliabilitas sebesar 0,896 (Tabel 2) yang artinya data tersebut memiliki tingkat reliabilitas yang baik, atau dengan kata lain data hasil instrumen tes dapat dipercaya.

Berdasarkan hasil analisis program ITEMAN version 3.00 diperoleh tingkat kesukaran soal (Mean $P$ ) sebesar 0.4I2. Berdasarkan Suharsimi Arikunto (2009:210), nilai ini menunjukkan bahwa soal yang diuji cobakan tergolong sedang karena berada pada ranah 0,3I - 0,70. Daya pembeda (Mean Biserial) soal yaitu sebesar 0.512. Hal ini menunjukkan bahwa daya pembeda soal tergolong baik yaitu berada para ranah 0,40 0,70 .

\section{Tabel 3. Hasil Uji Homogenitas Kelas VIIID dan VIIIF} One-Sample Kolmogorov-Smirnov Test

\begin{tabular}{lll}
\hline & VIIID & VIIIF \\
\hline $\mathrm{N}$ & 32 & 33 \\
Kolmogorov-Smirnov Z & I,I20 & I,I66 \\
Asymp. Sig. (2-tailed) &, I63 & ,I32
\end{tabular}

Soal yang diperoleh kemudian digunakan untuk pretest dan postest di kelas eksperimen dan kelas kontrol. Uji homogenitas dilakukan dengan One-Sample Kolmogorov-Smirnov test di kedua kelas dan dapat dilihat pada tabel 3. Data yang dipakai untuk uji homogenitas adalah data pretest. Jika nilai probabilitas atau signifikansi yang diperoleh $>0,05$ maka variansi setiap sampel sama (homogen). Nilai probabilitas pada kelas kontrol adalah 0,I63 dan pada kelas eksperimen 0,I32. Kedua nilai ini lebih besar daripada 0,05 sehingga disimpulkan bahwa kedua kelas yang digunakan merupakan kelas yang homogen.

Uji normalitas juga dilakukan dengan menggunakan OneSample Kolmogorov-Smirnov test di kedua kelas. Hasilnya dapat kita lihat pada tabel 4 .

Tabel 4. Hasil Uji Normalitas Kelas VIIID dan VIIIF One-Sample Kolmogorov-Smirnov Test

\begin{tabular}{lll}
\hline & VIIID & VIIIF \\
\hline $\mathrm{N}$ & 32 & 33 \\
Kolmogorov-Smirnov Z & 0,809 & $0,84 \mathrm{I}$ \\
Asymp. Sig. (2-tailed) & 0,530 & 0,478 \\
\hline
\end{tabular}

Data dikatakan berdistribusi normal jika probabilitas $(\mathrm{P})>$ 0,05. Berdasarkan hasil pengujian data pre-test pada kelas eksperimen dan kelas kontrol dengan menggunakan program SPSS 18.0, diperoleh nilai probabilitas sebesar 0,478 untuk pre- 


\section{Paired Samples Test}

\begin{tabular}{|c|c|c|c|c|c|c|}
\hline & \multirow{2}{*}{$\begin{array}{l}\text { Paire } \\
\text { d } \\
\begin{array}{l}\text { Differen } \\
\text { ces }\end{array} \\
\\
\text { Mean }\end{array}$} & \multirow[b]{2}{*}{$\mathrm{t}$} & \multirow[b]{2}{*}{$f^{d}$} & \multirow{2}{*}{\begin{tabular}{l}
\multicolumn{1}{c}{$\mathrm{S}$} \\
ig. \\
(2- \\
taile \\
d)
\end{tabular}} & \multicolumn{2}{|c|}{ Mean } \\
\hline & & & & & $\begin{array}{l}\text { pret } \\
\text { est }\end{array}$ & post \\
\hline $\begin{array}{ll} & \text { P } \\
\text { air } & \text { pretes } \\
\mathrm{I} & \text { posttest }\end{array}$ & $\begin{array}{c}- \\
34,063\end{array}$ & $\begin{array}{c}- \\
20,569\end{array}$ & $\mathrm{I}^{3}$ & $00^{, 0}$ & $\begin{array}{r}44 \\
, 47\end{array}$ & $\begin{array}{l}{ }^{7} \\
.53\end{array}$ \\
\hline
\end{tabular}

test pada kelas eksperimen dan pada kelas kontrol diperoleh nilai probabilitas sebesar 0,530 untuk pre-test. Kedua nilai ini jauh lebih besar dari 0,05 sehingga dapat dikatakan bahwa data yang diperoleh berdistribusi normal.

Kelas berdistribusi normal dan homogen oleh karena itu uji dilakukan dengan statistik paramatrik. Uji pertama yang dilakukan adalah paired samples t-test untuk kelas kontrol dan kelas eksperimen. Hal ini dilakukan untuk menentukan apakah ada perbedaan signifikan antara pretest dan postest. Uji dilakukan dengan paired (berpasangan) karena pretest dan postest dalam satu kelas merupakan pasangan awal dan akhir. Hasilnya dapat dilihat pada tabel 5 dan tabel 6 .

Tabel 5. Paired samples test kelas eksperimen

\begin{tabular}{|c|c|c|c|c|c|c|c|}
\hline $\begin{array}{l}\text { Paired } \\
\text { Sampl } \\
\text { es } \\
\text { Test }\end{array}$ & & & & & & & \\
\hline & & $\begin{array}{l}\text { Paired } \\
\text { Differenc } \\
\text { es }\end{array}$ & & & & \multicolumn{2}{|c|}{ Mean } \\
\hline & & Mean & $\mathrm{t}$ & $\begin{array}{l}d \\
f\end{array}$ & $\begin{array}{l}\text { Sig. } \\
(2- \\
\text { taile } \\
\text { d) }\end{array}$ & $\begin{array}{l}\text { prete } \\
\text { st }\end{array}$ & $\begin{array}{l}\text { poste } \\
\text { st }\end{array}$ \\
\hline Pair I & $\begin{array}{l}\text { pretest } \\
- \\
\text { postte } \\
\text { st }\end{array}$ & $\begin{array}{c}- \\
43,364\end{array}$ & \begin{tabular}{l}
\multicolumn{1}{c}{-} \\
20,56 \\
9
\end{tabular} & $\begin{array}{l}3 \\
2\end{array}$ & ,000 & $\begin{array}{l}39,7 \\
9\end{array}$ & $\begin{array}{c}83, \\
\mathrm{I} 5^{83}\end{array}$ \\
\hline
\end{tabular}

Tabel 5 memperlihatkan hasil uji paired sample t test untuk kelas eksperimen. Terlihat bahwa rata-rata nilai pre-test adalah 39,79 dan rata-rata kelas post-test adalah 83,I5. Kemudian pada tabel paired sample test terlihat bahwa nilai probabilitas yang diperoleh adalah 0,000. Nilai ini lebih rendah daripada 0,05 sebagai acuan patokan. Hal ini menunjukkan bahwa ada perbedaan signifikan antara pre-test dan post-test pada kelas eksperimen. Dengan kata lain pemahaman konsep dan aplikasi konsep siswa di kelas eksperimen meningkat.

Tabel 6 memperlihatkan hasil uji paired sample $t$ test untuk kelas kontrol. Terlihat bahwa rata-rata nilai pre-test adalah 44,47 dan rata-rata kelas post-test adalah 78,53. Kemudian pada tabel paired sample test terlihat bahwa nilai probabilitas yang diperoleh adalah 0,000. Nilai ini lebih rendah daripada 0,05 sebagai acuan patokan. Hal ini menunjukkan bahwa ada perbedaan signifikan antara pre-test dan post-test pada kelas kontrol. Dengan kata lain pemahaman konsep dan aplikasi konsep siswa di kelas kontrol meningkat.

\section{Tabel 6. Paired samples test kelas kontrol}

Uji gain-score dilakukan untuk mengetahui apakah ada perbedaan peningkatan pemahaman dan aplikasi konsep antara kelas eksperimen dan kelas kontrol. Uji gains skor ini menggunakan uji $t$ independent sample karena tidak ada hubungan antara gain skor kelas kontrol dengan kelas eksperimen (independen). Apabila Sig. (2-tailed) $<0,05$ maka pre-test dan post-test memiliki perbedaan yang signifikan dan sebaliknya. Hasil uji gain skor ini dapat dilihat pada tabel 7 .

Tabel 7. Independet samples t-test gain skor Independent Samples Test

\begin{tabular}{|c|c|c|c|c|c|c|}
\hline & \multicolumn{3}{|c|}{$\begin{array}{l}\text { t-test for Equality of } \\
\text { Means }\end{array}$} & \multicolumn{2}{|c|}{ Gain score } \\
\hline & & $\mathrm{t}$ & df & $\begin{array}{l}\text { Sig. } \\
(2- \\
\text { tailed })\end{array}$ & $\begin{array}{l}\text { eksperim } \\
\text { en }\end{array}$ & kontrol \\
\hline ain $^{g}$ & $\begin{array}{l}\text { EVA } \\
\text { EVNA }\end{array}$ & $\begin{array}{l}3,0 \\
58 \\
3,0 \\
61\end{array}$ & $\begin{array}{c}63 \\
62^{62,9}\end{array}$ & 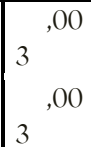 & 43,15 & 34,06 \\
\hline
\end{tabular}

Nilai rata-rata gain skor untuk kelas eksperimen adalah 43,I5 dan untuk kelas kontrol adalah 34,06. Berdasarkan perhitungan uji Independent sampels test diperoleh nilai probabilitas 0,003. Hal ini menunjukkan bahwa terdapat perbedaan gain-score yang signifikan antara kelas eksperimen dan kelas kontrol. Kelas eksperimen yang menggunakan modul pembelajaran sains dengan media pembelajaran gamelan menghasilkan kenaikan lebih tinggi daripada kelas kontrol yang menggunakan pembelajaran konvensional dengan buku.

Hasil postest juga menunjukkan bahwa 81,81\% siswa kelas eksperimen tuntas dalam belajar dan di kelas kontrol 78,62\% siswa tuntas dalam belajar dengan kriteria ketuntasan minimal 75 .

\section{v. Kesimpulan}

Kesimpulan dari penelitian ini adalah:

I. Kelas eksperimen menunjukkan rata-rata nilai pre-test adalah 39,79 dan rata-rata post-test adalah 83,I5. Paired sample test menunjukkan bahwa nilai probabilitas yang diperoleh adalah 0,000 menunjukkan bahwa ada kenaikan nilai pretest ke postest.

2. Kelas kontrol menunjukkan rata-rata nilai pre-test adalah 44,47 dan rata-rata kelas post-test adalah 78,53. Paired sample test menunjukkan bahwa nilai probabilitas yang diperoleh adalah 0,000 menunjukkan bahwa ada kenaikan nilai pretest ke postest.

3. Uji gain skor menunjukkan bahwa Nilai rata-rata gain skor untuk kelas eksperimen adalah 43,I5 dan untuk kelas kontrol adalah 34,06. Berdasarkan perhitungan uji Independent sampels test diperoleh nilai probabilitas 0,003. Terdapat perbedaan gain-score yang signifikan antara kelas 
eksperimen dan kelas kontrol. Kelas eksperimen yang menggunakan modul pembelajaran sains dengan media pembelajaran gamelan menghasilkan kenaikan pemahaman dan aplikasi konsep lebih tinggi daripada kelas kontrol yang menggunakan pembelajaran konvensional dengan buku.

\section{Kepustakaan}

Airasian, P. W et al, A Taxonomy for Learning Teaching and Assesing, A Revision of Bloom's Taxonomy of educational Objectives, Addison Wessley Longman inc, New York, 200I.

Bruce Joyce et al, Models of Teaching, Pustaka Pelajar Yogyakarta, 2009.

Dadan S, Merebut Kembali Kedaulatan Bangsa Melalui Ketahanan Budaya, Kordinator Cultural Security Discussion Group Indonesian Archipelago Culture Initiatives (IACI), 2008.

Eko Nursulistiyo, Pengembangan Modul Sains Dengan Media Pembelajaran Gamelan Untuk Meningkatkan Pemahaman Dan Aplikasi Konsep Getaran Gelombang Dan Bunyi Siswa SMP, Master, Thesis, 2012.

Imam Ghozali, Aplikasi Analisis Multivariate dengan program SPSS, Semarang: Badan Penerbit Universitas Diponegoro, 2001.

Louise Poulson \& Mike Wallace, Teaching \& Learning, SAGE Publications Ltd, London, 2004.

Paul Suparno, Metodologi Pembelajaran Fisika, Universitas Sanata Dharma, Yogyakarta, 2007.

Sofan Amri dan Iif Khoiru Ahmadi, Konstruksi Pengembangan Pembelajaran, Prestasi Pustaka Publisher, Jakarta, 2010.

Suharsimi Arikunto (2006. Prosedur Penelitian Suatu Pendekatan Praktek. Rineka Cipta, Jakarta, 2006.

JY, 2010, Gamelan Masuk Kurikulum di Amerika, http://oase.kompas.com/read/2010/07/15/03150118/Ga melan.Masuk.Kurikulum.di.Amerika, diakses tanggal I6 Juli 2010 